\title{
Pengujian outer model pada konstrak resiliensi
}

\author{
Rifa Nur Alifah \\ Magister Psikologi, Program Pascasarjana, Universitas Ahmad Dahlan \\ erifanuralifah@gmail.com \\ Fatwa Tentama \\ Magister Psikologi, Program Pascasarjana, Universitas Ahmad Dahlan \\ fatwa.tentama@psy.uad.ac.id \\ Nina Zulida Situmorang \\ Magister Psikologi, Program Pascasarjana, Universitas Ahmad Dahlan Yogyakarta \\ nina.situmorang@psy.uad.ac.id
}

\begin{abstract}
ABSTRAK
Guru sebagai manusia tentunya pernah dihadapi akan kesulitan dan tekanan, baik dalam kehidupan pribadi hingga dalam menjalani profesinya. Sehingga resiliensi dianggap penting untuk guru agar mampu menjalani kehidupan dan profesinya. Tujuan penelitian ini adalah menguji validitas dan reliabilitas konstrak resiliensi dan mengukur kontribusi aspek-aspek dan indikator-indikator dalam merefleksikan resiliensi. Subjek dalam penelitian ini adalah semua guru di sekolah X. Analisis data menggunakan uji outer model dengan program Smart PLS 3.0. Hasil analisis menunjukan instrumen telah valid dan reliabel untuk mengukur konstruk resiliensi, sehingga aspek dan indikator resiliensi diketahui dapat merefleksikan variabel resiliensi.
\end{abstract}

Kata Kunci: Guru, Outer Model, Resiliensi

\begin{abstract}
The teacher as a human being must have faced difficulties and pressures, both in his personal life and in his profession So that resilience is considered important for teachers to be able to live their lives and profession. The purpose of this study is to test the validity and reliability of the construct of resilience and measure the contribution of aspects and indicators in reflecting resilience. The subjects in this study were all teachers in school X. The data analysis used the outer model test with the Smart PLS 3.0 program. The analysis showed that the instrument was valid and reliable to measure the construct of resilience, so that aspects and indicators of resilience were known to reflect resilience variables.
\end{abstract}

Keywords: Teacher, Outer Model, Resilience.

\section{PENDAHULUAN}

Setiap manusia dalam menjalani kehidupan tentu pernah menghadapi kesulitan hingga tekanan, baik bersumber dari keluarga, lingkungan sosial hingga tempat kerja. Manusia dalam menjalani profesi pekerjaan apapun tentunya akan mendapatkan tantangan dan kesulitan masing-masing, begitu juga dengan guru. Guru berperan penting bagi kelangsungan pendidikan, walaupun dijaman modern ini banyak 
Jurnal Psikologi Terapan dan Pendidikan

ISSN: 2715-2456

Vol. 1, No. 1, Mei 2019, pp. 1-8

sumber bahan belajar seperti buku, internet, majalah dan lainnya peran seorang guru tidak dapat tergantikan karena proses pembelajaran tidak akan dapat berjalan secara maksimal (Sahlan, 2018).

Guru memiliki permasalahan yang beragam tentunya, dikutip dari kutipan rakyat bahwa masih ada sekolah yang belum terpenuhi fasilitasnya yaitu tidak memiliki ruang kelas sehingga guru mengajar di mushola sekolah (Arifianto, 2019). Kemudian permasalahan yang terjadi dikarenakan adanya perubahan kurikulum, maka guru dituntut harus mengikuti perubahan kurikulum dan kemajuan jaman namun kompetensi guru masih kurang, seperti yang dikutip di Republika (Murdaningsih, 2019). Selain itu permasalahan yang dihadapi guru dalam lingkungan sekolah yang dikutip di Oke News adalah hilangnya sopan santun siswa terhadap guru, menjadi tantangan tersendiri bagi guru dalam melaksanakan proses belajar mengajar (Agustian, 2018). Masih banyak lagi tentunya kesulitan hingga tantangan yang dihadapi seorang guru sebagai individualnya, yaitu permasalahan pribadi dalam kehidupannya yang kemungkinan akan berpengaruh pada perannya dalam menjalani profesi.

Menurut Beltman, Mansfield dan Price (2011) dalam menjalani profesinya sebagai pengajar, guru mengalami stres. Seharusnya guru memiliki resiliensi yang baik untuk bertahan dalam menghadapi tekanan dan tantangan, sehingga dapat menjalani profesinya. Berdasarkan penelitian yang dilakukan Arnup dan Bowles (2016), diketahui adanya faktor resiliensi yang rendah menyebabkan guru-guru mengundurkan diri dari profesinya. Didukung dengan hasil penelitian Richards, Bristol, Templin, dan Graber (2016), adanya tekanan peran yang tinggi pada guru maka membutuhkan resiliensi yang baik agar memiliki kepercayaan diri untuk mencapai harapan yang dinginkan.

Resiliensi menurut Connor dan Davidson (2003) merupakan ukuran kemampuan seseorang dalam mengatasi stres atau menghadapi tekanan, sehingga resiliensi dipandang penting dalam hal memulihkan kecemasan, depresi maupun reaksi stres. Individu yang memiliki resiliensi yang baik akan mampu melakukan adaptasi setelah melalui pengalaman yang tidak menyenangkan, sehingga psikologisnya tetap sehat dan stabil tidak mengalami stres maupun trauma dan dapat menjalani kehidupannya dengan baik. Menurut Gu dan Day (2013) resiliensi penting bagi guru untuk mempertahankan kapasitasnya dalam mencapai tujuan pendidikan. Kemudian berdasarkan hasil penelitian, diketahui dengan adanya resiliensi yang baik menunjukan ketangguhan guru ketika menghadapi kesulitan dalam menjalani profesinya yang terkait akan fasilitas sekolah, siswa, rekan kerja hingga sumber daya (Castro, Kelly \& Shih, 2010).

Menurut Connor dan Davidson (2003) resiliensi direfleksikan oleh lima aspek yaitu personal competence, trust in one's instincts, positive acceptence of change, control dan spiritual. Personal competence adalah standar tinggi dan sikap gigih seorang individu sehingga dapat mencapai tujuan walaupun mengalami atau menghadapi tekanan. Trust in one's instinct adalah keyakinan individu akan 
insting yang dirasakan, kemudian disertai kemampuan mentoleransi perasaan negatif sehingga tetap tenang dan mampu mengambil keputusan dalam situasi yang tidak menyenangkan.

Positive acceptence of change, merupakan gambaran individu yang dapat beradaptasi akan situasi yang tidak menyenangkan secara cepat dan memiliki hubungan yang baik dengan orang lain. Control ialah kemampuan individu untuk mengontrol strategi untuk mencapai tujuan dan sasaran yang jelas ketika menghadapi kesulitan atau keadaan yang tertekan, dan aspek yang terakhir ialah spritual yang meliputi kepercayaan individu akan peran tuhannya dalam mengatur dan berkehendak dalam kehidupannya (Connor \& Davidson, 2003).

Outer model merupakan model pengukuran untuk melihat validitas dan reliabilitas, terdiri dari validitas konstruk reflektif yang bersifat confirmatory untuk menunjukan seberapa baik hasil yang diperoleh dari penggunaan alat ukur dengan acuan teori yang digunakan dapat mendefinisikan suatu konstruk, dan reliabiltas dilakukan untuk menunjukan konsistensi internal alat ukur yaitu dengan meilihat nilai composite reliability dan cronbach's alpha dengan nilai yang lebih tinggi maka akan menunjukan nilai konsistensi dari masing-masing aitem dalam mengukur variabel (Jogiyanto, 2011).

Penelitian ini bertujuan menguji validitas dan reliabilitas konstrak resiliensi, untuk mengetahui kemampuan dan konsistensi instrumen dalam mengukur resiliensi dan bertujuan untuk mengukur kontribusi aspek-aspek dan indikator-indikator resiliensi dalam merefleksikan variabel resiliensi.

\section{METODE PENELITIAN}

Subjek dalam penelitian ini adalah guru di sekolah $\mathrm{X}$ dengan jumlah 66 orang guru. Instrumen yang digunakan pada penelitian ini adalah skala resiliensi yang dikonstruksi oleh penulis berdasarkan aspek-aspek resiliensi dari Connor dan Davidson (2003), yaitu personal competence, trust in one's instincts, positive acceptence of change, control dan spiritual. Skala resiliensi yang digunakan ialah skala dengan bentuk semantik diferensial yang memiliki format respon berupa pilihan jawaban dengan rentang angka 1-5, hal ini menunjukkan, apabila responden memilih rentang angka kearah kanan (favorable) mengindikasikan jawaban yang positif $(+)$ sedangkan apabila responden memilih rentang angka kearah kiri (unfavourable) mengindikasikan jawaban yang negatif (-). Adapun blueprint skala resiliensi yang telah disusun dapat dilihat pada Tabel 1. 
Jurnal Psikologi Terapan dan Pendidikan

ISSN: 2715-2456

Vol. 1, No. 1, Mei 2019, pp. 1-8

Tabel 1.

Blueprint Skala Resiliensi

\begin{tabular}{|c|c|c|c|c|}
\hline No. & Aspek & Indikator & $\begin{array}{l}\text { No. } \\
\text { aitem }\end{array}$ & Total \\
\hline 1. & Personal Competence & $\begin{array}{l}\text { a. Keyakinan akan kemampuan diri } \\
\text { b. Memiliki harapan tinggi }\end{array}$ & $1,2,3,4$ & 4 \\
\hline 2. & $\begin{array}{l}\text { Trust in one's } \\
\text { instincts }\end{array}$ & $\begin{array}{l}\text { a. Mampu mengatur emosi ketika } \\
\text { menghadapi kesulitan } \\
\text { b. Mampu mengambil keputusan ketika } \\
\text { menghadapi kesulitan }\end{array}$ & $5,6,7,8$ & 4 \\
\hline 3. & $\begin{array}{l}\text { Positive acceptence } \\
\text { of change }\end{array}$ & $\begin{array}{l}\text { a. Bersikap positif akan situasi yang } \\
\text { tidak menyenangkan } \\
\text { b. Kemampuan berdaptasi disituasi tidak } \\
\text { menyenangkan }\end{array}$ & $\begin{array}{l}9,10 \\
11,12\end{array}$ & 4 \\
\hline 4. & Control & $\begin{array}{l}\text { a. Mampu mengontrol strategi ketika } \\
\text { menghadapi kesulitan } \\
\text { b. Mampu membuat orang lain } \\
\text { mendukungnya ketika menghadapi } \\
\text { kesulitan }\end{array}$ & $\begin{array}{l}13,14 \\
15,16\end{array}$ & 4 \\
\hline 5. & Spritual & $\begin{array}{l}\text { a. Percaya akan adanya Tuhan } \\
\text { b. Keyakinan akan peran Tuhan dalam } \\
\text { mengatur hidupnya }\end{array}$ & $\begin{array}{l}17,18 \\
19,20\end{array}$ & 4 \\
\hline & Jumlah & & 20 & 20 \\
\hline
\end{tabular}

Penelitian ini utuk melakukan uji validitas dan reliabilitas dengan uji outer model menggunakan program Smart PLS 3.0 yang terdiri dari uji validitas konstruk reflektif yang bersifat confirmatory untuk menunjukan seberapa baik hasil yang diperoleh dari penggunaan alat ukur dengan acuan teori yang digunakan mendefinisikan suatu konstruk. Uji validitas konstruk yang dilakukan ialah validitas konvergen dengan meilihat nilai faktor loading $>0,5$, nilai average variance extracted (AVE) $>0,5$ dan validitas diskriminan dengan membandingkan akar average variance extracted (AVE) suatu konstruk harus lebih tinggi dibandingkan dengan korelasi antara variabel laten. Setelah itu dilakukan uji reliabilitas untuk menunjukan konsistensi internal alat ukur, dengan melihat nilai composite reliability dan cronbach's alpha menurut Cooper yaitu harus > 0,7 (Jogiyanto, 2011).

\section{HASIL DAN PEMBAHASAN}

Berdasarkan hasil analisis uji outer model menggunakan program Smart PLS 3.0, dapat diketahui validitas dan reliabilitas konstruk resiliensi telah terpenuhi, adapun outer model yang dihasilkan dapat dilihat pada gambar berikut: 


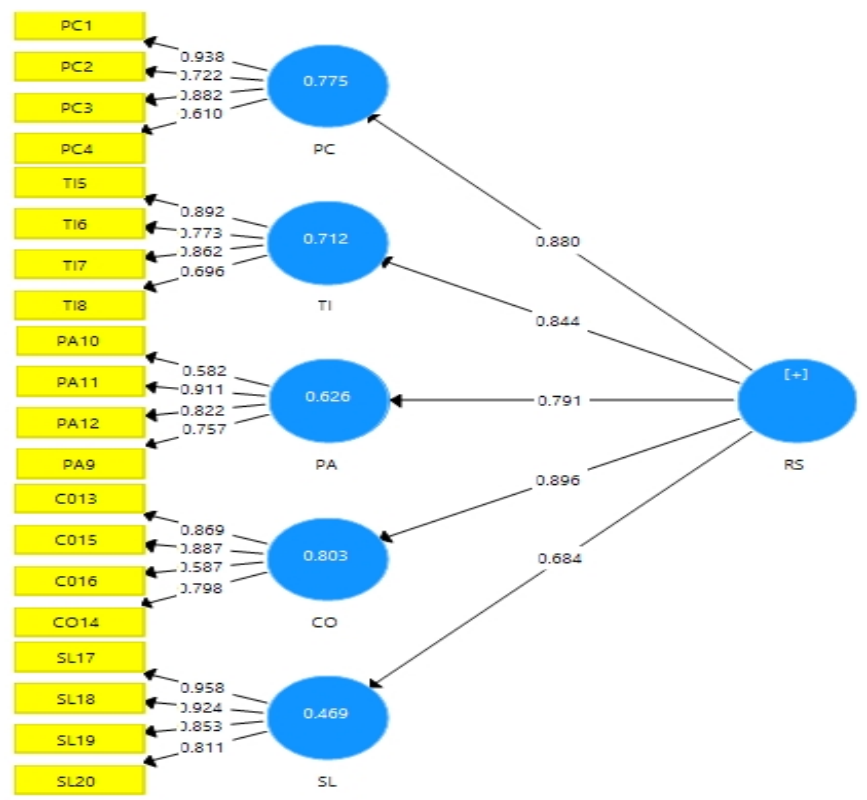

Gambar 1. Output Uji Outer Model Konstruk Resiliensi

Untuk menguji validitas konstrak, maka dilihat validitas konvergen yaitu memiliki nilai faktor loading $>0,5$ pada setiap aitem yang menurut Hair, dkk dianggap siginifikan dalam penelitian empirik (Jogiyanto, 2011). Diketahui semua aitem pada instrumen dinyatakan valid tidak ada yang gugur dapat dilihat pada tabel 2.

Tabel 2.

Nilai Faktor Loading

\begin{tabular}{ccc}
\hline Aitem & Nilai Faktor Loading & Keterangan \\
\hline PC1 & 0,938 & Sig \\
PC2 & 0,722 & Sig \\
PC3 & 0,882 & Sig \\
PC4 & 0,610 & Sig \\
TI5 & 0,892 & Sig \\
TI6 & 0,773 & Sig \\
TI7 & 0,862 & Sig \\
TI8 & 0,696 & Sig \\
PA9 & 0,757 & Sig \\
PA10 & 0,582 & Sig \\
PA11 & 0,911 & Sig \\
PA12 & 0,822 & Sig
\end{tabular}




\begin{tabular}{lll} 
CO13 & 0,869 & Sig \\
CO14 & 0,798 & Sig \\
CO15 & 0,887 & Sig \\
CO16 & 0,587 & Sig \\
SL17 & 0,958 & Sig \\
SL18 & 0,924 & Sig \\
SL19 & 0,853 & Sig \\
SL20 & 0,811 & Sig \\
\hline
\end{tabular}

Validitas konvergen dilihat juga berdasarkan nilai average variance extracted (AVE) yaitu $>0,5$ (Jogiyanto, 2011). Nilai AVE konstrak resiliensi telah terpenuhi, yaitu 0,736 > 0,5 dan nilai AVE setiap aspek dapat dilihat pada tabel 3

Tabel. 3 Nilai Avarage Variance Extracted (AVE) Konstruk Resiliensi

\begin{tabular}{lcc}
\multicolumn{1}{c}{ Aspek } & Nilai AVE & Keterangan \\
\hline Personal Competence & 0,637 & Sig \\
Trust in one's instincts & 0,655 & Sig \\
Positive acceptence of change & 0,604 & Sig \\
Control & 0,630 & Sig \\
Spritual & 0,789 & Sig \\
\hline
\end{tabular}

Selain validitas konvergen yang terpenuhi, validitas diskiriminan harus dilakukan karena pengukur-pengukur konstruk yang berbeda seharusnya tidak berkorelasi dengan tinggi. Caranya ialah dengan membandingkan nilai akar avarage variance extracted (AVE) setiap aspek, nilai antar aspek harus lebih tinggi dibandingkan dengan nilai akar aspek dengan aspek lain (Jogiyanto, 2011). Validitas diskriminan konstrak resiliensi telah terpenuhi, dapat dilihat pada tabel 4.

Tabel. 4 Nilai Akar Avarage Variance Extracted (AVE) Konstruk Resiliensi

\begin{tabular}{cccccc}
\hline Aspek & PC & TI & PA & CO & SL \\
\hline PC & 0,798 & 0,741 & 0,628 & 0,755 & 0,576 \\
TI & 0,741 & 0,809 & 0,729 & 0,772 & 0,482 \\
PA & 0,628 & 0,729 & 0,777 & 0,723 & 0,586 \\
CO & 0,755 & 0,772 & 0,723 & 0,794 & 0,616 \\
SL & 0,576 & 0,482 & 0,586 & 0,616 & 0,888 \\
\hline
\end{tabular}

Menurut Cooper reliabilitas instrumen dilihat berdasarkan nilai cronbach's alpha dan composite reliability yaitu $>0,7$ (Jogiyanto, 2011). Reliabilitas konstrak resiliensi telah terpenuhi dengan nilai composite reliability dan cronbach's alpha $>0,7$ dapat dilihat pada tabel 5.

Tabel. 5

Nilai Cronbach's Alpha Konstrak Resiliensi 
Jurnal Psikologi Terapan dan Pendidikan

ISSN: $2715-2456$

Vol. 1, No. 1, Mei 2019, pp. 1-8

\begin{tabular}{cccc}
\hline Variabel & Composite Reliabelity & Cronbach's alpha & Keterangan \\
\hline Resiliensi & 0,943 & 0,928 & Reliabel \\
\hline
\end{tabular}

Untuk mengetahui seberapa besar masing-masing aspek dalam merefleksikan resiliensi maka menurut Hartono dengan melihat nilai T-statistics yaitu harus lebih tinggi dibandingkan nilai T-table dengan tingkat keyakinan 95\% (alpha 5\%) yaitu >0,96 (Jogiyanto, 2011). Pada konstrak resiliensi diketahui semua aspek memiliki nilai T-statistics lebih besar dari $>0,96$ (Tabel 6). Semua aspek dapat merefleksikan resiliensi, aspek yang paling dominan dalam merefleksikan resiliensi adalah aspek control dengan nilai T-statistics 37.185 dan aspek yang paling lemah adalah spiritual yaitu dengan nilai $T$ statistics 4.698.

Tabel.6

Nilai T-statictics Konstruk Resiliensi

\begin{tabular}{lccc}
\hline \multicolumn{1}{c}{ Aspek } & Nilai T-Statictics & P Values & Keterangan \\
\hline Personal Competence & 23,595 & 0,000 & Sig \\
Trust In One's Instinct & 25,167 & 0,000 & Sig \\
Positive Acceptence Of Change & 19,838 & 0,000 & Sig \\
Control & 37,185 & 0,000 & Sig \\
Spiritual & 4,698 & 0,000 & Sig \\
\hline
\end{tabular}

\section{KESIMPULAN}

Uji outer model konstrak resiliensi menggunakan program Smart PLS 3.0 menunjukan bahwa skala resiliensi yang disusun penulis dapat digunakan secara maksimal sebagai alat untuk mengukur resiliensi pada guru. Resiliensi di refleksikan oleh lima aspek pembentuk resiliensi yaitu personal competence, trust in one's instincts, positive acceptence of change, control dan spiritual. Aspek yang dominan merefleksikan resiliensi adalah aspek control sedangkan aspek paling lemah adalah aspek spiritual. Bagi peneliti selanjutnya disarankan untuk memahami konsep teoritik resiliensi dan konsep model yang digunakan, agar disesuaikan dengan kondisi internal subjek.

\section{DAFTAR PUSTAKA}

Agustin, W. (2018). Hilangnya sopan santun siswa. Dikutip 25 Juli 2019 dari Oke News. https://news.okezone.com/read/2018/12/05/65/1987099/hilangnya-sopan-santun-siswa .

Arifianto, B. (2019) . Ruang kelas kurang, siswa SDN 3 Salawu Kabupaten Tasikmalaya belajar di musala sekolah. Dikutip 25 Juli 2019 dari Pikiran Rakyat. https:/www.pikiranrakyat.com/jawa-barat/2019/07/23/ruang-kelas-kurang-siswa-sdn-3-salawu-kabupatentasikmalaya-belajar-di-musala-sekolah

Arnup, J \& Bowles, T. (2016). Should i stay or should i go? resilience as a protective factor for teachers' intention to leave the teaching profession. Australian Journal of Education, 60(3), 229-244. DOI: $10.1177 / 0004944116667620$ 
Vol. 1, No. 1, Mei 2019, pp. 1-8

Beltman, S., Mansfield, C. and Price, A. (2011) Thriving not just surviving: A review of research on teacher resilience. Educational Research Review, 6(3),185-207. http://dx.doi.org/10.1016/j.edurev.2011.09.001

Connor, K. M \& Davidson, J. R. T (2003). Development of a new resilience scale: The connor-davidson resilience scale (CD RISC). Deppresion and Anxiety 18, 76-82. DOI: 10.1002/da.10113

Castro, A. J., Kelly, J., \& Shih, M. (2010). Resilience strategies for new teachers in high-needs areas. Teaching and Teacher Education, 26, 622-629. doi:10.1016/j.tate.2009.09.010.

Gu, Q., \& Day, C. (2013) Challenges to teacher resilience : Conditions count. British Educational Research Journal, 39(1), 22-44. http://dx.doi.org/10.1080/01411926.2011.623152

Jogiyanto. (2011). Konsep dan aplikasi structural equation modeling berbasis varian dalam penelitian bisnis. Yogyakarta: STIM YKPN.

Murdaningsih, D. (2019). Rendahnya kompetensi guru menjadi permasalahan pendidikan Indonesia. $\begin{array}{lllll}\text { Dikutip } & 25 & \text { Juli } & 2019 & \text { dari }\end{array}$ https://republika.co.id/berita/pendidikan/eduaction/pq53k5368/rendahnya-kompetensi-gurujadi-masalah-pendidikan-indonesia

Richards, K. A.R., Bristol, C.L.,Templin, T. J., \& Graber, K. C. (2016). The impact of resilience on role stressors and burnoutin elementary and secondary teachers. Social Psychology of Education 19(3), 511-536. DOI 10.1007/s11218-016-9346-X

Sahlan, A. K. (2018). Mendidik perspektif psikologi. Yogyakarta: Deepublish. 